\title{
Transformation of Aerodynamic Capture Principle to Dynamic Activation of Fuel Mixture principle, Program and Associated Method of Preliminary Tests
}

\author{
Victor Popov \\ Master of Engineering in Computer Science, Cornell University, New York, \\ United States of America \\ Bachelor's Degree in Mechatronics and Robotics, Bauman Moscow State \\ Technical University, Moscow, Russian Federation
}

\begin{abstract}
In the device for testing of air-fuel mixture activation method it is suggested to use the real structural system of aerodynamic jet grip which is connected to a compressor and inserted to the pipeline of a specific configuration that is filled with gasoline. While inside a pipeline with gasoline, the aerodynamic jet grip foams it and the foam goes up the pipe from where it can be collected for analyzes and experiments. In this device it is possible to adjust the most important parameters such as compressed air pressure and cross-sectional area of the pipeline, where the second fuel component is stored, which give specific properties for activated fuel mixture. Furthermore, adjustment of some other dimensional parameters and proportions of aerodynamic jet grip details can result in different levels of fuel mixture activation.
\end{abstract}




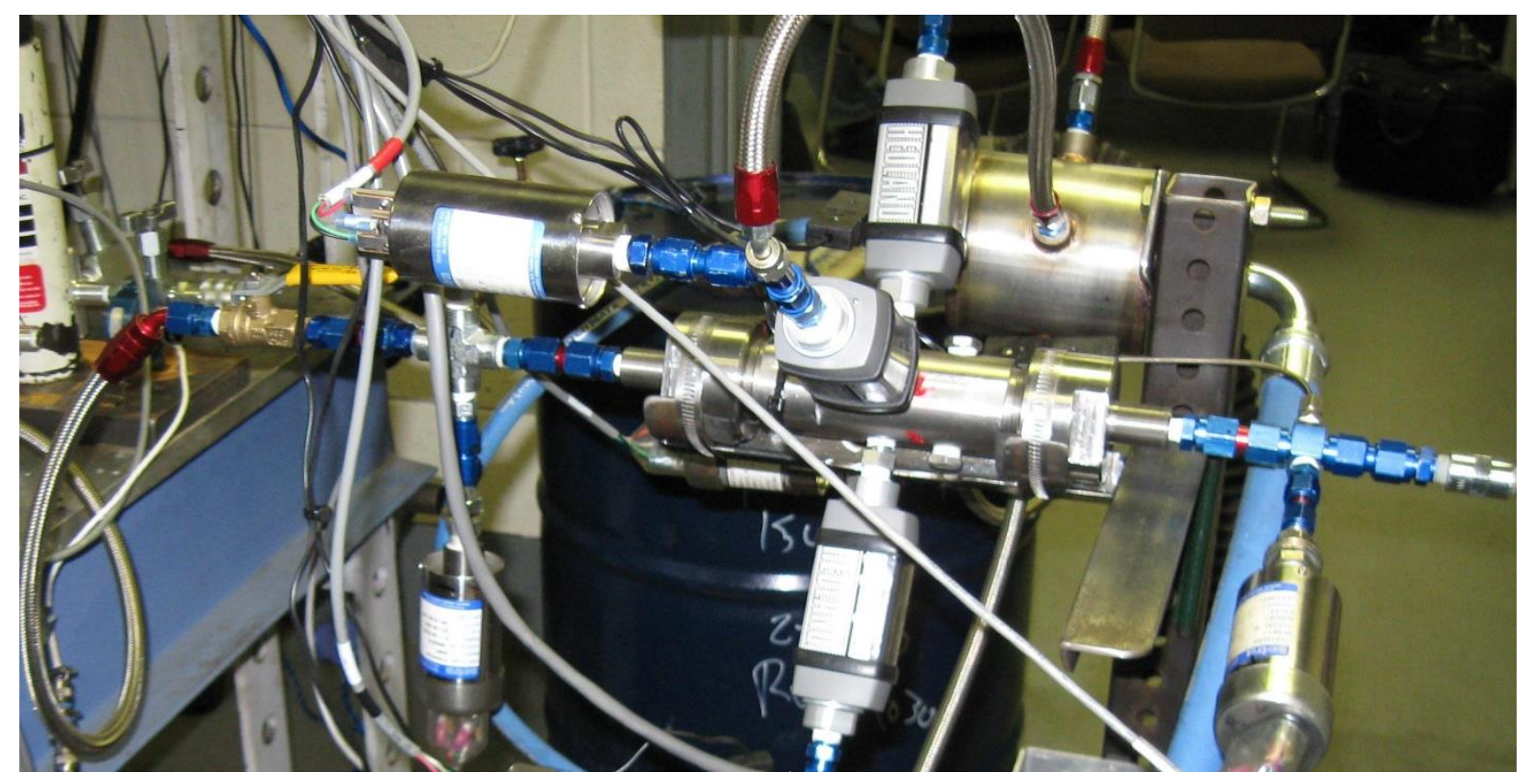

Figure 1. Part of testing rig with apparatus for dynamic activation of fuel mixture

1. Brief Description of imitation method principle.

Imitation of aerodynamic fuel mixture activation method is a process of controlled supply of compressed air into the enclosed volume of fuel mixture that is located in the pipeline of testing device. The device structure has a particular structure of pipelines which is connected with atmosphere in the vertical parts of the pipeline.

2. Main tests of mixing proportions of fuel mixture components.

Aerodynamic principle for mixing different components of fuel mixture can be used in the device. In order to do so, the control tap should be opened by eighth, fourth, half and three fourth from the fully opened state while maintaining the compressed air pressure. In each state of the tap the activated foamed mixture is collected for analysis, kept for the required reactivation time and then volume and weight proportions of the fuel mixture components are measured. 


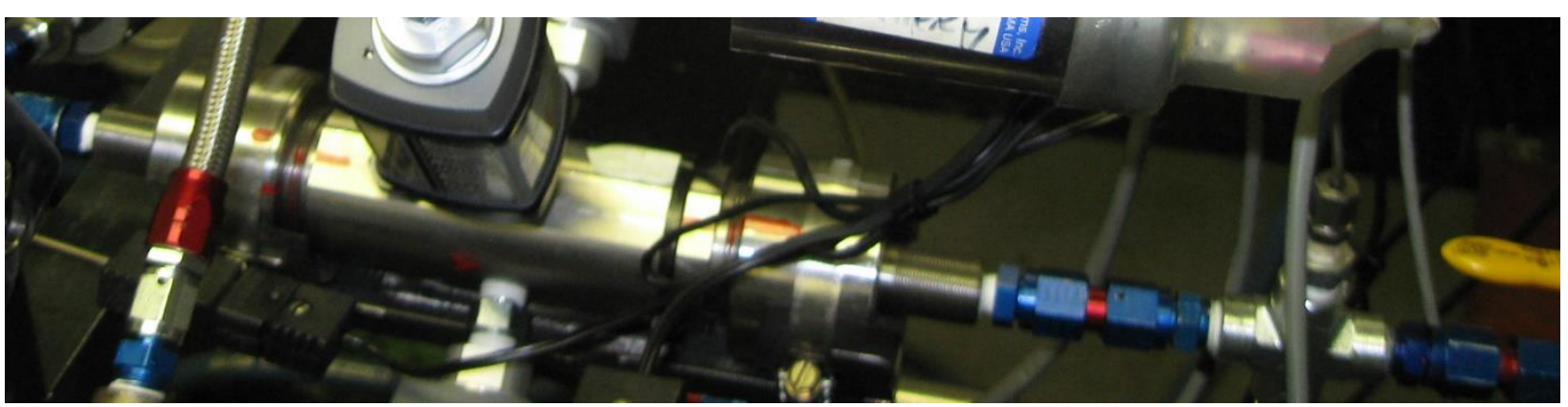

Figure 2. Construction for fuel mixture dynamic activation

3. Main tests of volume proportions of fuel mixture components as a function of compressed air pressure.

For this test, given a particular position of the control tap, a compressed air pressure is changed in the following range: 4 bar, 5 bar, 6 bar, 7 bar and 8 bar. For each of aforementioned pressures a sample of activated fuel mixture is taken, kept for the required reactivation time and after that volume and weight proportions of the fuel mixture components are measured.

4. Main tests of stability preservation time of the fuel mixture in foamed state as a function of compressed air pressure.

For these series of tests the same device preparation is needed as described in item 3 and an activated fuel mixture sample is collected and the time which is required for its complete reactivation is measured.

5. Main tests of stability preservation time of the fuel mixture in foamed state as a function of components proportion.

For these series of tests the proportion of fuel mixture components is changed using the control tap and controlling the compressed air pressure. For each case a sample of activated fuel mixture is taken and the time which is required for its complete reactivation is measured.

6. Main tests of stability preservation time of the fuel mixture in foamed state as a function of components temperature.

For these series of tests the device is filled with the components having the temperature in the following range (in Celsius): 20 degrees, 30 degrees, 40 degrees and 50 degrees. For each of the aforementioned temperatures a sample of activated fuel mixture is taken and the time which is required for its complete reactivation is measured. 


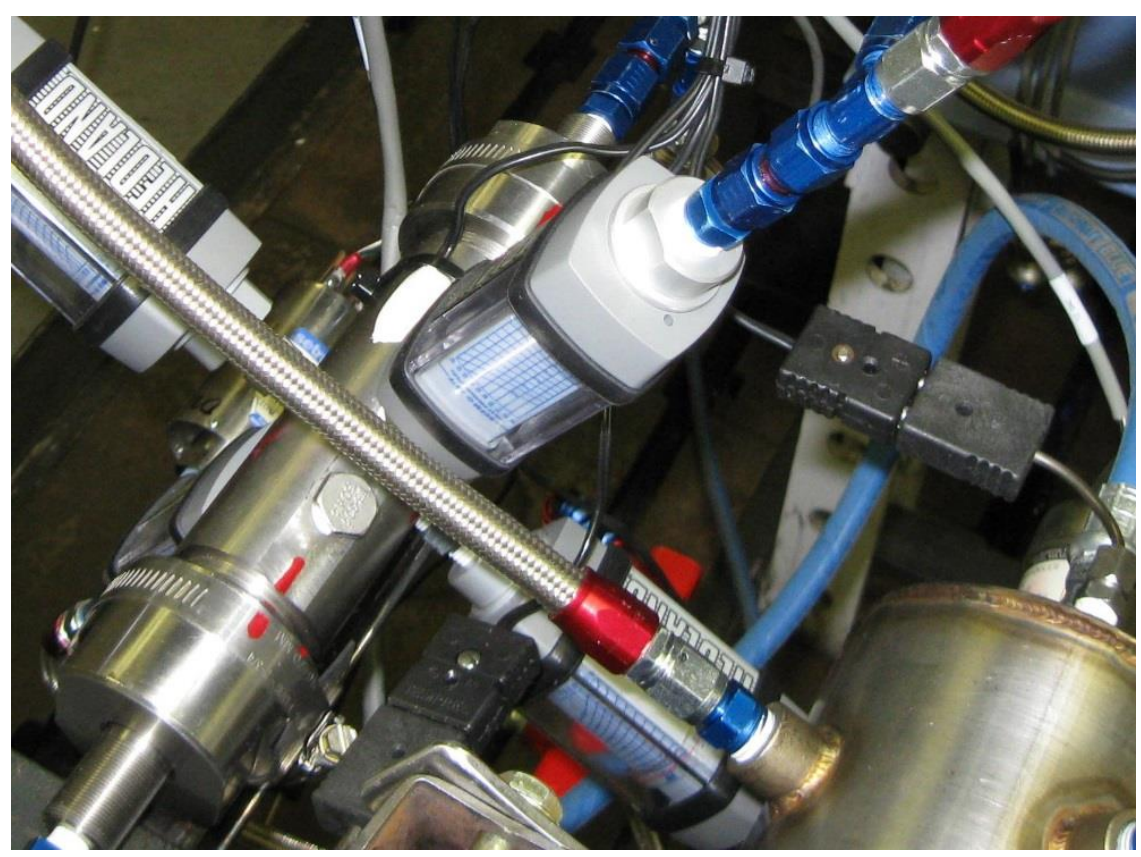

Figure 3. Construction of device for dynamic fuel mixture activation with compressed gas consumption sensors.

7. Main tests of heating effect of fuel mixture for different values of the compressed air pressure.

For this test the same device preparation and setup is needed as described in item 3. Then a sample of fuel mixture is collected and burned in laboratory reactor and heating effect parameters and time transients are determined in accordance with laboratory instruments specification.

8. Main tests of heating effect of fuel mixture for different concentrations of its organic components.

For this test different organic components of fuel mixture such as gasoline, etanol and diesel fuel are mixed, then the resulted mixture is activated and the heating effect of the fuel mixture is determined in accordance with procedure described in item 7.

9. Main tests of heating effect of fuel mixture for different mixture proportion of its organic and anorganic components.

For this test the device for changing proportions in fuel mixture components is prepared. For each proportion a sample of activated fuel mixture is collected and burned in the laboratory reactor and heating effect parameters are determined in accordance with instructions specified 
in the laboratory instruments specification. For mixing the main component (gasoline, etanol or diesel fuel) with an auxiliary component which is water. The water in each experiment should have different properties such as tap water, purified water, water without ions, condensed water vapor from any air conditioning system, water containing brass ions of concentration 10 milligrams/liter, water containing brass ions of concentration 20 milligrams/liter, water obtained from desalination of sea water and water mixed with alcohol in different proportions.

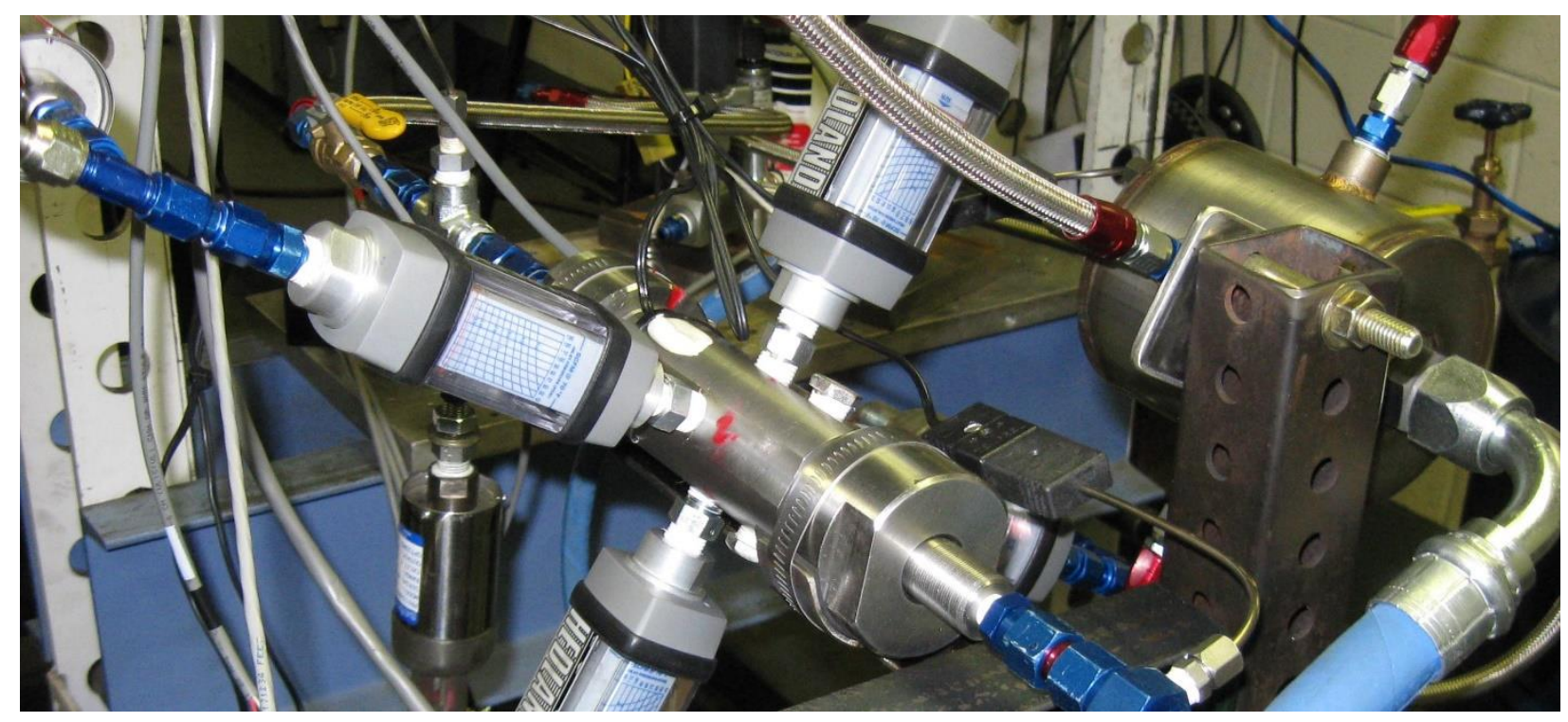

Figure 4. Device for dynamic manipulation on fuel mixture via homogeneous dynamic mixing of fuel mixture stream with compressed air.

10. Main parameters tests for items 3-9 for different constructions of aerodynamic activator case.

In construction of the aerodynamic activator case variable parameters may take place resulting in different output parameters and traits of all aerodynamic activator. These parameters are:

- Diameter of holes in the case;

- Number of holes in the case;

- Diameter of the case head, where the membrane is mounted;

Diameter of holes in the case may vary in the following range: $1 \mathrm{~mm}, 2.5 \mathrm{~mm}$ and $2 \mathrm{~mm}$; Number of holes in the case may vary in the following range: 6 holes, 8 holes and 12 holes. Diameter of the case head, where the membrane is mounted may vary in the following range: $15 \mathrm{~mm}, 20 \mathrm{~mm}$ and $25 \mathrm{~mm}$. 
11. Main tests of fuel mixture parameters for items 3-9 for different constructions of aerodynamic activator membrane.

In aerodynamic activator membrane construction functional abilities can be changed via the following variable parameters:

- Membrane thickness;

- Distance from membrane to aerodynamic activator case;

- Membrane diameter;

- Active area of the membrane;

All of aforementioned parameters effect to different extent the efficiency of membrane operation and the whole aerodynamic activator. Adjustment of these parameters results in different levels of foaming efficiency and different values of fuel mixture parameters from items 3-9.

Parameters values:

- Membrane thickness: 0,25 mm;0,35 mm;0,5 mm; 0,75 mm;

- Distance from membrane to aerodynamic activator case: 0,05 mm;0,1 mm; 0,15 mm; $0,2 \mathrm{~mm}$;

- Membrane diameter: $15 \mathrm{~mm} ; 20 \mathrm{~mm} ; 25 \mathrm{~mm}$;

- Active area of the membrane: $30 \% ; 40 \% ; 50 \%$;

12. Test of NOx gas concentration that is remained after burning of a fuel mixture sample for different constructions of a testing device and different parameters and results of a fuel mixture activation process.

For each of the cases the concentration of specified gas that is remained after burning of an activated fuel mixture sample is determined using the laboratory equipment.

13. Test of NOx gas concentration that is remained after burning of a fuel mixture sample for different mixing proportions of organic and anorganic components of fuel mixture. Mixing proportions:

- Gasoline: 95\%; water: 5\% ;

- Gasoline: 90\%; water: 10\%; 
- Gasoline: $80 \%$; water: 20\%;

For every provided mixing proportion the activated fuel mixture sample is collected and the specified gas concentration after burning of activated fuel mixture is measured using laboratory sensors for gas concentration analysis.

14. Test of NOx gas concentration that is remained after burning of a fuel mixture sample for different mixing proportions of organic components of fuel mixture.

This test should be performed using the analogous procedure to item 13 .

Main distinctive characteristics of a complex device for fuel mixtures activation:

1. The device has a complex combined effect on the fuel mixture and its components.

2. The device has several consecutive functions of fuel mixture type and properties transformations. Furthermore, all steps of the specified transformations are held inside a device in a state of constant motion of the base material and additional fuel mixture components.

3. While manipulating the fuel mixture components, the device can operate simultaneously with liquid and gas mediums, i.e. at any time of working cycle there is a simultaneous and synchronous manipulation on both liquid and gas fuel mixture components. Furthermore, each of the components by itself manipulates and effects the characteristics of other components and resulting characteristics of a fuel mixture when it is injected into the combustion chamber.

4. Effect of mixture components as parts of activated fuel mixture on its properties and characteristics, conditions of operation and its efficiency are preserved even after injection into the combustion chamber.

5. Addition of both liquid and gas components to the stream of fuel mixture is done via tangential channels with creation of a swirling effect. 
6. A device for complex activation has 10 consecutive interrelated steps of shape and cross-section transformation that only in combination achieve the specified goals and attempts of examining them separately without fully functional connection with others is erroneous.

7. The purpose of the device is not an increase of turbulence level, but complex effect, which includes several crucial technological methods such as transformation of input stream shape and characteristics, forming a zone with high level of local turbulence and addition to this zone of additional liquid fuel components via swirling effect, following by formation in this zone of a second spot of rarefication via addition of a compressed air stream with preliminary formed turbulence level and swirling effect, which completes the formation of activated fuel mixture and provides its dispersive separation after injection into combustion chamber.

8. By the physics laws and principles it is known that inside a pipeline the motion of a liquid that contacts the pipeline wall has a developed turbulence structure.

9. In the device the purpose of stream cross-section shape transformation is to transform the stream shape from circular to annular which leads to the $\mathrm{x} 2.5$ increase of a contact perimeter and to the consequent increase of a stream turbulent properties.

10. As compressed gas is added to the device in a state of a developed turbulent stream via swirling principle, the rate of accumulated turbulence and kinetic energy in fuel mixture grows exponentially.

11. As the stream of compressed gas is added into the hermetic volume under the initial pressure of 20 atmospheres and at the device input it creates a local annular zone which has main properties of a locally rarefication in accordance with Bernoulli principle and eponymous theorem, the air bubbles are detached from the stream and they are covered by a coat of liquid fuel mixture components. Furthermore, the pressure grows inside a 
bubble because a liquid is incompressible and during the time of a pause between injections, the air is still added which leads to increase of number of bubbles and the pressure inside them also increases. As a result, there is an unstable turbulent state in the mixture, which after the injection into the combustion chamber leads to destruction of bubble walls and increase in dispersity level of fuel mixture before ignition.

\title{
LIST OF LITERATURE, PATENTED AND LICENSED MATERIALS
}

\section{APPENDIX 1}

United States Patent Application

20190161188

Kind Code

Device for Propelling a Passenger

\begin{abstract}
The invention relates to a device for propelling a passenger, comprising a body arranged to receive said passenger and cooperating with a fuel-fed thrust unit. The arrangement of such a device enables great freedom of movement in the air. More specifically, the thrust unit comprises at least one thrust sub-unit, each advantageously comprising at least two thrusters and secondary course-correction and/attitude-correction thrusters.
\end{abstract}

\section{APPENDIX 2}

United States Patent Application

20190153965

Kind Code 


\title{
CONTROL DEVICE FOR INTERNAL COMBUSTION ENGINE AND CONTROL METHOD FOR INTERNAL COMBUSTION ENGINE
}

\begin{abstract}
An internal combustion engine in which when an ECU receives an engine stop command by an $\mathrm{ON}$-operation of an engine stop switch, a supply of fuel from an injector to a fuel reformation chamber is stopped while a supply of fuel from an injector to a combustion chamber is continued, and the residual amount of a reformed fuel in passages is estimated, in this state. When the estimated residual amount reaches a predetermined amount or zero, the fuel supply from the injector to the combustion chamber is stopped, and an internal combustion engine is stopped.
\end{abstract}

\section{APPENDIX 3}

United States Patent Application

20190145342

Kind Code

JACOBSSON; Susanna ; et al.

May 16, 2019

\section{METHOD AND SYSTEM FOR CONTROLLING THE AMOUNT OF FUEL IN CONNECTION TO OPERATING AN INTERNAL COMBUSTION ENGINE}

\begin{abstract}
The present invention relates to a system, method, and computer program product for controlling the amount of fuel in connection to operating an internal combustion engine based upon engine boost pressure and engine operational conditions using a map function. The engine operational conditions comprise engine speed and ambient air pressure. The method comprises: for low and/or negative engine boost pressures using a map function specifying torque values so as to determine an available torque based upon an exhaust gas smoke limit taking driveability into account; and determining a maximum allowable fuel amount based upon said determined available torque considering losses and combustion efficiency.
\end{abstract}




\title{
APPENDIX 4
}

United States Patent Application

20190107040

Kind Code

A1

Tsumura; Yuichiro

April 11, 2019

\section{CONTROL DEVICE FOR COMPRESSION SELF-IGNITION ENGINE}

\begin{abstract}
A compression self-ignition engine performs a SI combustion in which an air-fuel mixture is combusted due to flame propagation triggered by spark ignition, and a CI combustion in which the air-fuel mixture is combusted due to self-ignition induced by the flame propagation. An ECU comprises a first control means for controlling a SI ratio serving as an index relating to a ratio of a heat amount generated in the SI combustion with respect to a total heat amount generated in the SI and CI combustions or a heat amount generated in the CI combustion; and a second control means for controlling an in-cylinder temperature before the SI combustion. The ECU is configured to change a combustion state of each of the SI and CI combustions by both the first and second control means according to the operating state of the engine.
\end{abstract}

\section{APPENDIX 5}

United States Patent Application

20190055485

Kind Code

A1

Kasai; Jun ; et al.

February 21, 2019

\section{PULVERIZED-FUEL SUPPLY UNIT AND METHOD, AND INTEGRATED GASIFICATION COMBINED CYCLE}




\begin{abstract}
A pulverized-fuel supply unit includes a hopper, first nozzles, second nozzles, a pressurizinggas supply device, a fluidization-gas supply device, and a pulverized-fuel supply line. The hopper has a hollow to store therein pulverized fuel. The first nozzles are provided to the hopper. The second nozzles are provided to a vertically lower part of the hopper below the plurality of first nozzles. The pressurizing-gas supply device is configured to supply pressurizing gas to increase internal pressure of the hopper. The fluidization-gas supply device is configured to supply fluidization gas to fluidize the pulverized fuel in the hopper. The pulverized-fuel supply line is provided to a vertically lower part of the hopper. The pressurizing-gas supply device supplies pressurizing gas to the first nozzles and the second nozzles. The fluidization-gas supply device supplies fluidization gas to the second nozzles.
\end{abstract}

\title{
APPENDIX 6
}

United States Patent Application

20190078517

Kind Code

HEBERT; Jeremie ; et al.

March 14, 2019

METHOD AND SYSTEM FOR DIRECTING FUEL FLOW TO AN ENGINE

\begin{abstract}
Systems and methods for directing fuel flow to an engine when the engine is in an electronic manual override mode are described herein. In accordance with an aspect, a commanded fuel flow to the engine is determined from a fuel schedule based on the position on an engine control lever; a limit is applied on the commanded fuel flow when the commanded fuel flow exceeds a maximum fuel flow threshold; and fuel flow is directed to the engine based on the commanded fuel flow.
\end{abstract}

\section{APPENDIX 7}




\title{
FUEL CONTROL SYSTEM
}

\begin{abstract}
A fuel control system is provided for a gas turbine engine having a core engine comprising at least one core engine spool in which a compressor and a turbine are interconnected by a shaft. The system includes a first engine sensor which determines a power output of the engine. The system further includes a control unit which is configured to compare the determined power output with a value of a power threshold, and to command a reduction in fuel supplied to the engine when the determined power output exceeds the power threshold value. The system further includes a second engine sensor which measures the rate of change of rotational speed of the core engine spool. The control unit is further configured to adjust the power threshold value as a function of the measured rate of change of speed of the core engine spool.
\end{abstract}

\section{APPENDIX 8}

United States Patent

Application

20190003406

Kind Code

Kjemtrup; Niels ; et al.

January 3, 2019

LARGE TWO-STROKE COMPRESSION-IGNITED INTERNAL COMBUSTION

ENGINE WITH FUEL INJECTION SYSTEM FOR LOW FLASHPOINT FUEL AND A

FUEL VALVE THEREFORE

Abstract 
A large two-stroke turbocharged compression-ignited internal combustion crosshead engine with a plurality of cylinders has at least one pressure booster for each cylinder for boosting fuel pressure, two or more electronically controlled fuel valves for each cylinder with an inlet of the two or more electronically controlled fuel valves being connected to an outlet of the at least one pressure booster. An electronic control unit is connected to the at least one pressure booster and the two or more electronically controlled fuel valves. The electronic control unit is configured to determine a start time for a fuel injection event, activate the at least one pressure booster ahead of the determined start time and pen the two or more electronically controlled fuel valves at the determined start time. 